\title{
Product and supply chain related data, processes and information systems for product portfolio
}

\section{management}

\begin{abstract}
Traditional Product Data Management (PDM) systems have evolved to support the Product Lifecycle Management (PLM). The combination, also referred to as PDM/PLM has developed into a product master data (PMD) repository. The PMD and business process related data are utilised in product portfolio management (PPM). However, companies' tendency to have productrelated data in silos among multiple business processes and information systems (IS) results in uncertain information for PPM. This study focuses on data, processes and information systems related to PMD and supply chain product data (SCPD), PPM and supply chain (SC) processes and information systems. The study highlights the related challenges in providing fact-based data for PPM analysis and decision-making. The results indicate that the key PMD and SCPD have not been connected back to PPM as automated and integrated data flow from enterprise resource planning (ERP) system to the PDM/PLM system. The key SCPD consists of product-related volume and cost information that should be linked to PPM analysis and decision making. These findings are critical to further develop data, processes and IS to support strategic and financial PPM analysis and decision making on what products a company should have in the portfolio.
\end{abstract}

Keywords: Product portfolio management, Product Lifecycle Management, Product Master Data, Supply chain product data, Supply chain process, Product data management, Enterprise resource planning. 


\section{Introduction}

The number of products and services has been growing during the last decades especially in the company level (Tolonen et al. 2015b), which in turn increases the amount of data on products and services. Companies are forced to use specific Product Data Management (PDM) systems to manage product master data (PMD) (Silvola et al. 2011). PDM systems manage the information about a product across its lifecycle (Stark 2011). The utilisation of PMD in different lifecycle phases (development, maintain, warranty, and archive) also increases the amount of supply chain product data (SCPD). However, the role of supply chain related master data has not been adequately discussed in the previous literature. According to Stark (2011), "PLM is the business activity of managing, in the most effective way, a company's products all the way across their lifecycles; from the very first idea for a product all the way through until it is retired and disposed of. PLM manages both individual products and the Product Portfolio, the collection of all of a company's products." (Stark 2011). Product lifecycle management (PLM) has been identified as one of the key concepts that can support the aims to improve product quality, time-to-market and costs within manufacturing industries (Sriti et al. 2015; Marchetta et al. 2011; Saaksvuori and Immonen 2008). The PLM is simply necessary to master the definition of existing products, to further design product functionalities and to ensure efficient product deliveries, maintenance, and support (Saaksvuori and Immonen 2008). The literature either refers to the concepts of PDM and PLM separately or as a combination PDM/PLM to represent a tightly coupled, combined set of PLM solutions with a PDM backbone (Stark et al. 2014; Weber and Werner 2003).

All enterprise data need to be treated as a strategic asset (Aiken and Billings 2013), including product-related master data through the entire product lifecycle phases (Silvola 
et al. 2018). Product lifecycles have been defined in several ways depending on the source. One way is to categorise them into five phases; imagine, define, realise, support/use, and retire/dispose (Stark 2016), or planning, introduction, growth, mature, and decline (Saaksvuori and Immonen 2008; Kotler and Armstrong 2011). Another alternative way is to split them into four main phases, which are product development (PD), maintain (active product sales and delivery), warranty (warranty, spare part and repair services) and archive (product data store without any business activities) (Tolonen et al. 2014).

The organisation level product portfolio consists of new incoming products under development and existing products in the launch and later life cycle phases (Haines 2008). Two major important abilities have been recognised during the product lifecycle; to be good at replacing aging products with newly developed ones, and to strategically resonate with changing tastes, technologies, and competition in the market (Kotler and Armstrong 2011). One of the further challenging issues in product development (PD) also involves predicting how the new product affects the existing product portfolio (Srinivasan et al. 2005). Product portfolio management (PPM) should be the method which continuously seeks strategic, market related, financial and operational balance throughout the entire lifecycle of products and on an organisational level (Haines 2008). Indeed, the PPM is a dynamic analysis and decision-making process, where active new products and PD projects are regularly followed, and necessary actions carried out accordingly (Cooper et al. 1999; 2001). By examining it more widely, it is possible to see how PPM is a decision-making process to gather and analyse the facts about company's products to be developed, marketed, sold, delivered, maintained, and removed during the lifecycle according to the company strategic PPM targets and key performance indicators (KPIs) (Tolonen et al. 2015a). The strategy should be further converted to objectives and measures throughout 
the entire organisation (Haapasalo et al. 2006; Porter 1996), where metrics and strategy are closely connected (Haapasalo et al. 2006; Hulthén et al. 2016). It is also important to link the strategy with operational management at all levels of the organisation (Haapasalo et al. 2006). Also, the product configuration strategy and a generic product structure concept should be extended to support all product types, i.e., hardware, software, and services, or any combination of them (Kropsu-Vehkapera et al. 2011).

Product cost is one fundamental factor for the PPM analysis and decision making during the entire product lifecycle. The product profitability comes from product cost subtracted from the product sales price. The lifecycle cost (LCC) models have been referenced, e.g., by Doros et al. (2014) and by Dunk (2004), which take into account the total costs of the product or service from conception until disposal. The products assumed to be profitable can be noticed unprofitable especially when the total LCC are calculated. (Doros et al. 2014). Heller et al. (2014) note that the total cost of products typically focuses mainly on production expenses. (Heller et al. 2014). Dunk (2004) refers to LCC model from manufacturer's perspective, where total costs are generated from overall planning, design, testing, production, marketing, distribution, administration, service, and warranty costs. The borderline between functional area costs and lifecycle costs is not clear (Dunk 2004). It is all-important to figure out the expected revenues and occurring costs when estimating the business case for the PD project. However, a standpoint is often limited to manufacturing and assembly costs. (Heller et al. 2014).

Based on the above background, this study focuses on challenges in PMD, SCPD and related processes and information systems to provide fact-based information for PPM. The target of the study can be scoped following research questions:

RQ 1: What are the elements to provide supply process-related information for PPM? 
RQ 2: What are the current challenges in these issues in companies?

Our research originates from the literature review on RQ1 to create the theoretical framework for the empirical case study on three international companies. For the RQ2 we analyse the connection of SCPD to PMD for the PPM analysis and decision-making in case companies.

\section{Earlier research}

This chapter discusses several concepts that relate to this study. These concepts include master data and master data management (section 2.1), closed-loop PLM (section 2.2), product portfolio management (section 2.3), and product-related data in business processes (section 2.4). In section 2.5 the concepts for product and supply chain related data, processes and information systems are synthesised according to the focus of this study.

\subsection{Master data and master data management.}

Kumar Das and Mishra (2011) define master data as cleansed, standardised, and enterprisewidely integrated critical business information (e.g., product master data, vendor master data, and customer master data) in companies' transactional and analytical operations. Master data management (MDM) connects applications and technologies to synchronise organisations' applications, business processes, and analytical tools resulting in improvements in operational efficiency and reporting as well as supporting strategic decision-making. (Kumar Das and Mishra 2011). Silvola et al. (2011) present the one master data framework consisting of three key elements, which are data, processes, and information systems (IS). The key challenge is to define master data clearly and by this way make the overall data quality better. (Silvola et al. 2011). Kropsu-Vehkapera et al. (2011) highlight the importance of the general product structure concept and configuration 
logic of products in a company throughout the entire product portfolio, starting with company strategy and business (Kropsu-Vehkapera et al. 2011). A product structure concept is a typical way of modeling products; it represents the backbone of the company's business (Kropsu-Vehkapera et al. 2009). A clear product structure definition and configuration logic is necessary for effective MDM. Product master data (PMD), the master data that relates to products has been defined by Silvola (2008) as follows: "Product master data entails the data that is produced during the PD phase. Data that is then released to be used in other corporate functions and business processes. This data is validated in different development phase milestones and steering group meetings to ensure the deliverable content meets the use phase expectations of the business processes. Product master data is often stored in PDM/PLM systems. The quality of the product master data should not be compromised, and the data should be commonly understandable."

\subsection{Closed-loop PLM.}

Closed-loop PLM allows feeding necessary information back to designers and production engineers from any stage of the product lifecycle (Jun et al. 2007). Kiritsis (2011) defines the concept of closed-loop PLM as a system, where everyone (e.g., managers, designers, service, and maintenance operators) can track, manage, and control product related information during the entire lifecycle. Several recent researches associate the benefits of the closed-loop PLM process as information tracked, managed and controlled during the product lifecycle phase (Berriche et al. 2016; Borgia et al. 2015; Daaboul et al. 2016; Kubler et al. 2016; Shin et al. 2015). These studies are approaching certain business processes, such as, design and production (Berriche et al. 2016), reverse logistics design (Daaboul et al. 2016), design modification based on found defective design parameters from product usage data (Shin et al. 2015), supporting the redesign phase of a complex 
product according to the feedback data (Borgia et al. 2015), and requirement engineering framework (Kubler et al. 2016). All of the studies mentioned above state, more or less, that "closing the loop" permits the access to all data during the lifecycle of the products instead of one specific stage, and hence has a positive cost impact, and shorten the development cycles. Hadaya and Marchildon (2012) state, that both new product market performance and product development capabilities are higher when supporting product chain by closedloop PLM process instead of utilising the traditional PLM process only. They also state that by encouraging operational integration within the product lifecycle, significant financial and nonfinancial benefits could be achieved based on the PLM approach. (Hadaya and Marchildon 2012). Nonetheless, the research is lacking in taking into account the effect of closed-loop PLM on PPM.

\subsection{Product portfolio management.}

According to Cooper et al. (2001), the deficient PPM can result in serious negative consequences. Despite this, PPM is commonly poorly understood and deployed as PD projects are not selected based on PPM criteria of strategic fit, value maximisation and portfolio balance (Cooper et al. 2001). Deficient PD project go/kill decisions result in suffering projects. The lack of PPM leads to too many projects and ineffective resource usage, causing time-to-market delays, poor quality, and overall selection of wrong projects based on political, opinion-based and emotional criteria. (Cooper et al. 2001). Several studies show that the importance of PPM is not clearly understood, and strong product management policies are missing from organisations. (e.g., Haines 2008; Tolonen et al. 2014; Cooper et al. 2001). Portfolio level decision making is challenging based on fluctuating and compelling circumstances and with too many conflicting goals by multiple stakeholders within the organisation. (Cooper et al. 2001). Despite the size, maturity or 
history of the company PPM is a generic challenge for businesses. Many companies have only company level profitability measurement based on company-specific data and reporting structures, non-clear portfolio and sub-portfolio definitions including their ownership, the growing size of product portfolios and cannibalisation between products, lack of PPM processes and lack of clear PPM governance models. (Tolonen et al. 2014). Cooper et al. (2001) specify three PPM criteria as a) strategic fit, b) value maximisation and c) portfolio balance. Since earlier PPM research has been focusing mainly on PD lifecycle, Tolonen (2016) proposes to widen the PPM scope horizontally over the entire lifecycle of the products as well as vertically to cover both commercial and technical product portfolios according to the company strategic PPM targets and KPIs. (Tolonen 2016). Also, Tolonen et al. (2015b) broaden the perspective to cover PPM criteria by the nine components of the mission statement. These are; 1) market segments, 2) customers, 3) products, 4) technology, 5) economic success, 6) competitive advantage, 7) values, 8) public image and social responsibility, and 9) employees.

\subsection{Product Related data in business processes}

The most of the PMD is created during the PD phase since PDM systems were originally designed to store engineering product data in the 1980s. In parallel with PDM system evolution, several other enterprise solutions were introduced, such as enterprise resource planning (ERP) for the supply chain process and customer relationship management (CRM) for the sales process. Each of them is dependent on PMD and product-related business process information. (Ameri and Dutta 2005). The original PMD, however, has not been fully capitalised in the sense of using it in collaboration for key business units together with the key business processes, such as sales process, supply chain process, care and service processes, and support processes (i.e., human resources, finance \& control). 
Companies hence have several different "data silos" (e.g., Jetson and Nelis 2008; Kumar Das and Mishra 2001) that are just partly connected but do not cover the full product lifecycle from the cradle to the grave. According to Madenas et al. (2014), despite the wide range of systems used, the product data and business process related product data are locked in several repositories, and the information is difficult to share. Several software systems, tools, and methods are used to maintain PMD and related business data. These include, e.g., computer-aided design (CAD), computer-aided engineering (CAE), PLM/PDM, CRM, ERP, finance and control (F\&C), and service and care related systems and applications. Also, experimental data with a different format in various databases are collected by several company departments during the product lifecycle (Borgia et al. 2015). However, this has caused several issues, such as interoperability, redundant information exchanges, and interconnecting systems in all lifecycle stages (Marchetta et al. 2011; Sriti et al. 2015).

\subsection{The construction of product and supply chain related data, processes and}

\section{information systems for PPM}

According to the focus of this study, the concepts of 1) product and supply chain related data, 2) processes and 3) information systems are linked in Figure 1 to enable understanding of their interrelation. The construction is created in line with Silvola et al. (2011; 2018). Since there is lack of consistent terminology in the existing literature, this construction defines first two types of master data, product master data (PMD) and supply chain product data (SCPD), that link to PPM and SC processes and the related PDM/PLM and ERP information systems. Based on this construction, the SCPD data should provide the volume and cost-related information for PPM analysis and decision-making. The product-related cost and volume data can be seen as a key SCPD for PPM. 
Figure 1. Construction created for Product master data, supply chain product data and related processes and information systems for product portfolio management.

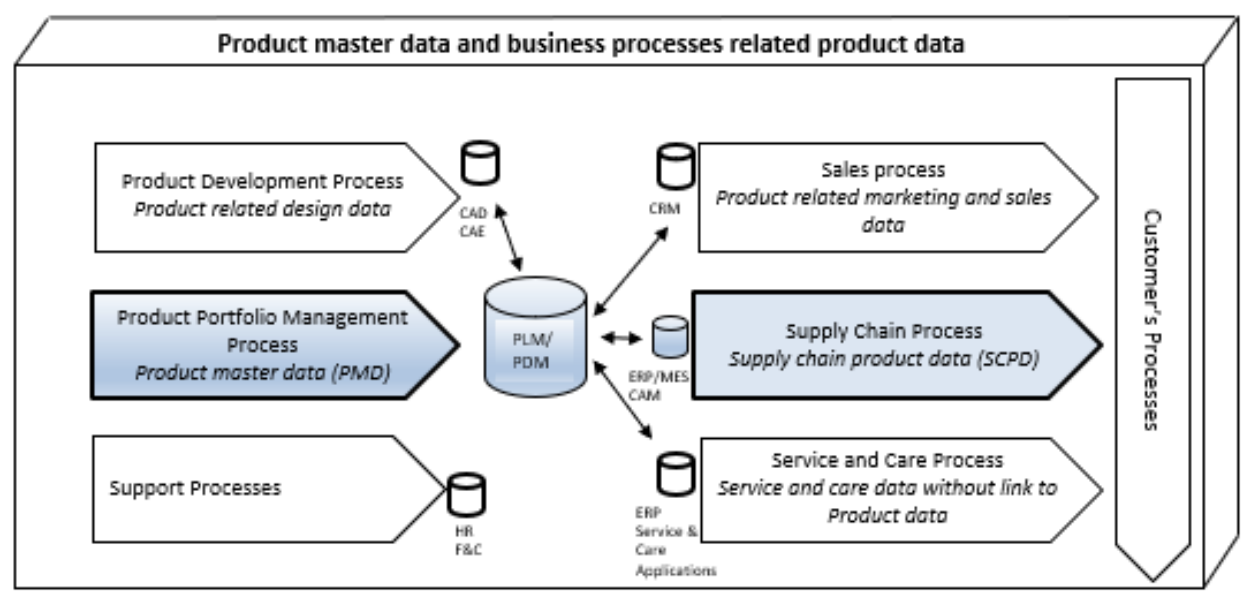

\section{Research process}

The research approach in this study involves the existing literature review, creation of new construction for empirical current state analysis and empirical qualitative analysis of the current practices and challenges in three international companies to provide SC processrelated cost information for PPM analysis and decision making. The research process is shown in "Figure 2". As a first research step, the existing literature was reviewed covering necessary concepts in master data management (MDM), PPM, and supply chain (SC) business processes and related information systems. Since the main purpose of this study is the analysis of the role of the PMD and supply chain related product data for PPM the development of the new construction was created as a second research step. The empirical current state analysis in case companies was then implemented as a third research step to reveal the current challenges. The results as current practices and challenges to provide the 
product related cost information in the SC process for PPM are presented as the main result of the study. Finally, the conclusions of the study were created.

Figure 2. The research process.

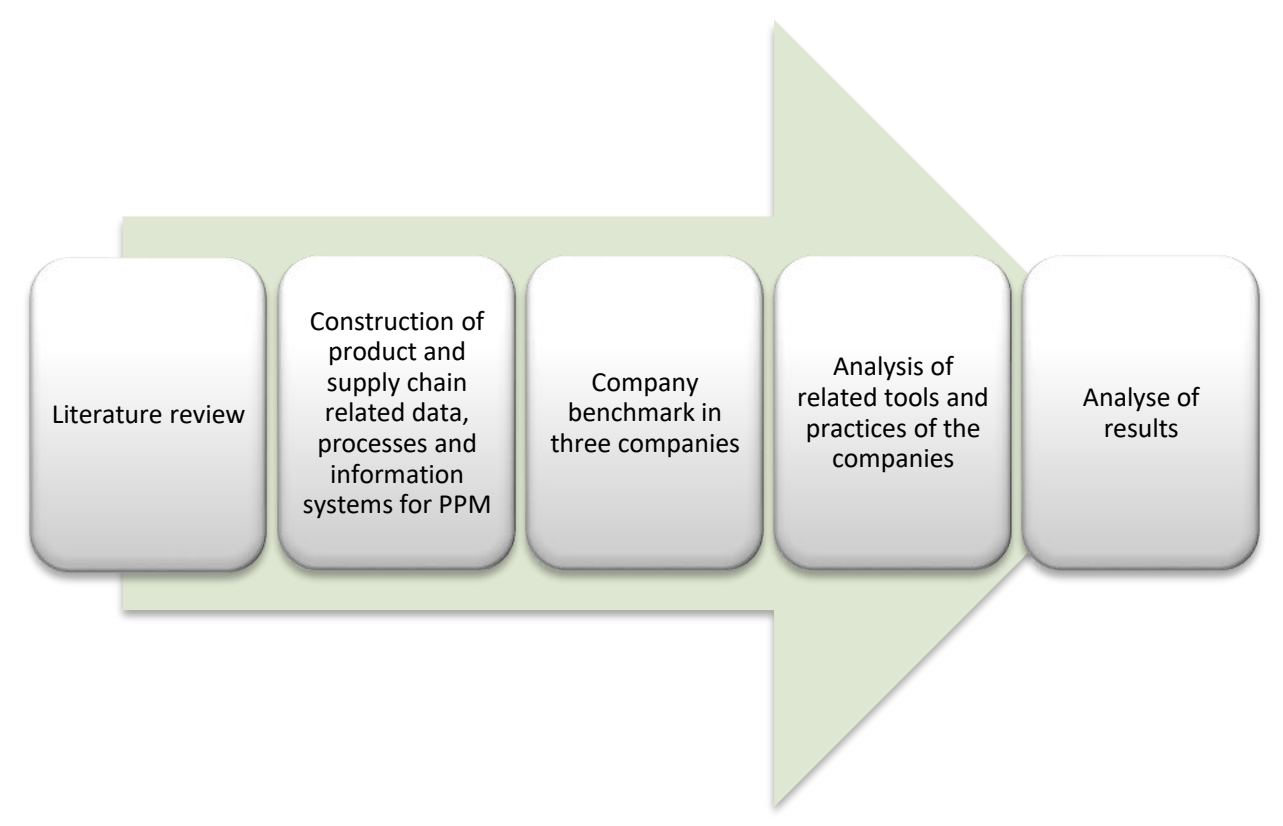

Three international companies were benchmarked by means of a two-day workshop in each to discuss the studied matters. Table 1 summarises a common characteristic of the benchmarked companies. The company A is a high-volume manufacturer of HW products and is the market leader in a very competitive industry. The company B manufactures customer and OEM products including HW, SW, and solutions. The company C is one of the world's leading manufacturers in its business sector and exports configurable products to over 100 countries. Their products consist of $\mathrm{HW}$ and SW, and they also have pure HW and SW products in their product portfolio. 
Table 1. Common characteristics of the case companies.

\begin{tabular}{c|ccc}
\hline & Case A & Case B & Case C \\
\hline \# of employees & 12000 & 1300 & 2700 \\
\# of manufacturing & & & 3 \\
sites & & 3 & \\
\# of distribution & & & 20 \\
centers & Ho & & \\
Product & HW & HW, SW, and & HW, SW, and \\
& Mature, global & Mature, long & Mature, global \\
Business maturity & leader with a long & business history & leader with a long \\
& business history & & history \\
Business type & OEM & B2B, B2C, OEM & B2B \\
Markets & Global & Global & Global \\
Benchmark & Two days & Two days & Two days \\
\hline
\end{tabular}

This study focused on PDM/PLM systems, tools, and methods that are used to create and maintain PMD. All the necessary documentation of the common IS landscape, and related process descriptions were analysed as a part of the benchmark in each of the companies. Every single tool was analysed regarding usage, i.e., what is the role of the tool in PMD management, how the PMD is classified and in which tool or system, which is the original source of PMD and is there any additional tools (e.g., Excel spreadsheets or corresponding) used. Additionally, the integrations and data transfers between tools and systems as well as PMD governance models were analysed. The participants in benchmarks represented persons from engineering (electrical and mechanical designers), product/project 
management, product data/product portfolio management, IS, and finance. After the workshop, a set of additional interview questions were presented during semi-structured interviews (Merton et al. 1990) to fully understand the big picture of IT system landscape related to tools and their integrations utilised for PMD. These tools consist of CAD, PDM/PLM, ERP, PPM, and CRM. The companies were also interviewed about the cost and sales price calculation practices of their products and MDM practices both on the system and on an enterprise level. Informants in interviews are shown in appendix A, and the related questionnaire in appendix B. Interviews were transcribed during the interview sessions, and the mutual understanding was ensured after every session.

\section{Results and analysis}

Each of the analysed companies has a variety of IS tools implemented and interfacing with each other; these tools are shown in Table 2. The integration between E/MCAD tools and PDM system interlinked with ERP seems to be a common IS landscape in the analysed companies. The product structure and related bill of material (BOM), representing the technical engineering structure, composed in a PDM system are further transferred into ERP. Nonetheless, the amount of tools used varies between companies. For example, the company A is using two separate PDM systems; one for electrical engineering and another for mechanical engineering. Also, the initial BOM creation is done in MS Excel; i.e., the same data is stored in several systems. However, changing data in one system may cause deviations in another system. There is no connection to original electronic parts at the system level until the final BOM creation; the data copied into an Excel spreadsheet remains a copy, and the connection to the original data is later lost. Despite two different PDM systems, the engineering data is fragmented outside the PDM system which causes many challenges during the engineering phase. 
Table 2. Main PDM/PLM tools used for PMD and SCPD in case companies

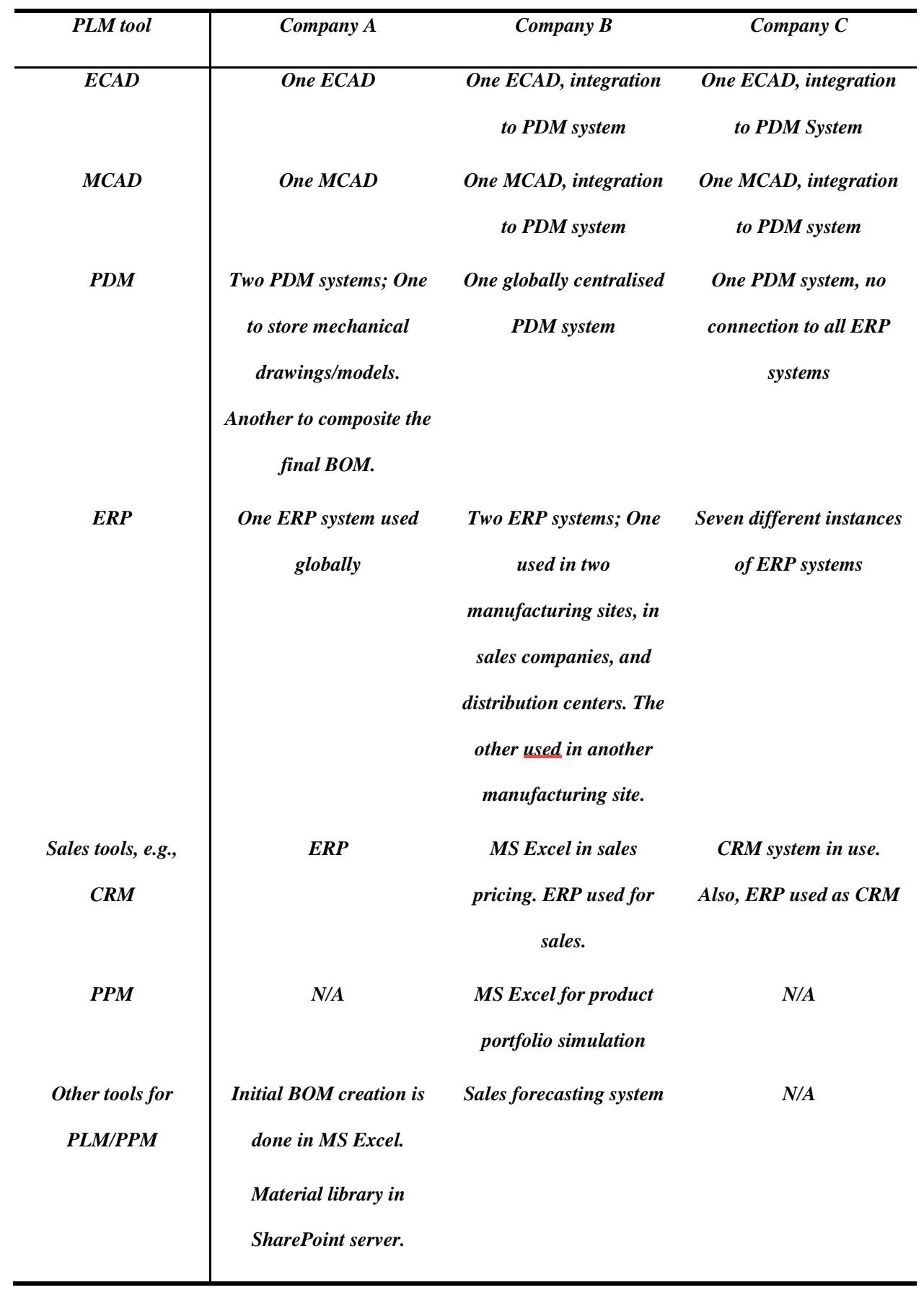


The product lifecycle cost (LCC) calculation in company A is done in an Excel spreadsheet. LCC costs consist of the material, manufacturing, delivery, PD, and some additional cost elements related to the customer contracts. The product cost consists of the material, manufacturing, and delivery costs and it is maintained in ERP.

The company $\mathrm{B}$ has a common engineering product structure for all its main products. The products of the company consist of $\mathrm{HW}, \mathrm{SW}$, and solution. The SW inside the $\mathrm{HW}$ is an individual item in product structure but maintained in a separate system. The product structure is created in one globally centralised PDM system, which is integrated with ECAD and MCAD. The final product structure is further transferred into an ERP system. Items and item attribute values are transferred one direction; from PDM to ERP.

The product manufacturing cost is calculated and maintained in ERP in the company B. The cost consists of HW components added by manufacturing costs. The SW cost is included in the PD project cost. The post-sales costs - such as SW maintenance, service, delivery, and warranty costs - are not linked to the product cost or the product lifecycle cost. These are rather categorised as other functional expenses.

The direct costs of the products are maintained in the ERP system in a company C. The company $\mathrm{C}$ has two different ways for pricing; standard pricing by product features, and pricing based on product unit. The LCC of the products are not systematically followed as such currently, but these are roughly estimated in financial reports: "We do not follow the LCC of products. We kind of think the product as an investment... we put a certain amount of capital to the product development and follow later from financial reports how we are progressing with the product (Interviewee in company C)". The additional design costs or software maintenance costs after product launch are not allocated to the LCC of the product. 
The MDM practices vary between the analysed companies. However, the MDM concept development was recognised as one of the future development targets in each of the companies. Company A has not initiated any systematic actions in this area yet, and also the data ownership was not clearly defined: "At the moment we have too many systems to maintain product data and product master data. Also, we neither have MDM definitions nor clear responsibilities regarding data ownership. This is recognised as one of the development targets in the near future. Since we have a target to get rid of another PDM system and centralise the product data management to one PDM system, we have to conceptualise the MDM before that (Interviewee in company A)". Company B has implemented MDM concept on a system level for PDM and ERP, but the enterprise level definition is missing: "We had a massive project several years back to specify all product data attributes in use; what is the original system the attribute is created? Which system is the master system for the attribute? Who is the owner of data/attribute? Moreover, who is responsible for keeping the data/attribute maintained? On a system level, this works well, but we do not have enterprise level visibility for this (Interviewee in company B)". Company $\mathrm{C}$ is aiming to initiate MDM project on a corporate level. They are facing duplicate items based on different ways to create items in different business units of the company. In the worst cases, they have had two different item codes for one single product.

Based on this study it was obvious that the potential of all tools used was not identified, e.g., BOM creation in company A was done in Excel spreadsheet even two separate PDM systems were available, where the BOM/product structure creation is one of the core functionalities. The interviewee in a company A said: "During the years the lack of common corporate level governance model has led to the situation, that product data and product master data is maintained in too many systems and the full potential of IS investment has not been realised. We aim to centralise product data to one system, also for 
financial reasons since we have to currently pay double license costs (Interviewee in company A)". Since the master data was not clearly identified, it was fragmented in several systems. This causes, among other things, invisibility between business processes and data processes. Company $\mathrm{C}$ lacked corporate level MDM guidelines, and for that reason, items were created differently between subsidiaries. None of the case companies were following the total LCC of products systematically.

The main findings of company analyses that reveal the PPM and supply process related challenges can be summarised as follows:

1) PMD is fragmented into several IS and tools. Siloed PMD and partly connected enterprise solutions are causing interoperability and redundant information exchanges.

2) SCPD is not defined regarding supply process related product data. There is no consistent definition in the existent literature.

3) The total LCC of products is not calculated systematically. The product cost consists mainly of direct material costs added by manufacturing costs.

4) Companies have not adequately connected SCPD back to PDM/PLM for PPM analysis and decision making. The connection between PDM/PLM and SCPD is needed to further develop the fact-based and real-time PPM.

\section{Discussion}

This study recognises the role of PMD and SCPD including related processes and information systems as the key concepts for more fact-based PPM. These can also be seen as the key elements for providing supply process related information for PPM. The two 
types of master data, PMD and SCPD link the supply chain processes, and the related PDM/PLM and ERP information systems. It is the SCPD that should provide the volume and cost-related information for PPM analysis and decision-making. This is emphasised by the current reality presented in all the analysed companies. Companies seem to have a wide variety of PDM/PLM and ERP systems, tools, and methods implemented and more or less integrated with each other. Also, the PMD and SCPD data remains fragmented into different enterprise solutions causing interoperability and unnecessary information exchanges between systems. The fragmentation of data within and outside enterprise solutions, and the lack of considering the wider perspective with the information systems are among the company challenges. This results in poor visibility over data through the entire organisation. Certain visibility over data would be necessary to support the factbased analysis of the product portfolio. The product related volume and cost information is needed. The necessary SCPD exists in the used ERP systems, and the PMD in the PDM/PLM systems. However, currently, the role of the SCPD for PPM analysis and decision making is neither recognised nor connected back to PLM to support PPM analysis and decision making. PMD and SCPD being defined inadequately in companies is also a challenge for utilising the data for fact-based analysis and decision-making. The lack of PLM governance model and clearly defined responsibilities and data ownership are resulting in issues such as duplicate item creation and delays in item and product structure updates. Also, much time is wasted in making sure the validity of data, especially in case if the business-critical data is stored in spreadsheets.

The loose connection or even no connection between real lifecycle costs, sales price, and profit targets is resulting in the situation where companies are not able to report product level profitability in their product portfolios. This is a challenge from the PPM perspective. Roughly generalising, the profitability of the product can be specified based on maximum 
agreed product cost versus minimum sales price allowed for sales. Typically, mainly production expenses are included when calculating the total cost of products. This even if considering all costs, starting from planning through design, manufacturing, delivering, maintaining, and warranty has been proposed and would be well justified. It is, however, important to note that the boundary between functional area costs and lifecycle costs is often unclear. Hence, it is vital to evaluate the expected revenues and estimate total occurring costs even in the planning phase of the PD project.

The inadequate definition of master data being a challenge, the MDM concept is recognised as one of the most important areas to be further developed in all the analysed companies to reach the full potential of realised data assets. This forms the foundation to develop further PPM analysis and decision-making processes and tools. Poor MDM is seen to waste resources and to make the data unreliable. The role of MDM is also seen important due to it forming a connection between applications, business processes, and analytical tools.

This study highlights the necessity of defining PMD and SCPD in companies and feeding the necessary SCPD back to PDM/PLM system, to enhance operational efficiency and to support fact-based and real-time PPM analysis and decision-making. The current research is lacking in analysing the relationship between centralised MDM, PMD, and SCPD, emphasising the necessity of further research in this area, particularly due to the business importance of the issue.

\subsection{Scientific implications}

This study creates a new construction that allows perceiving Product Master Data (PMD) and supply chain product data (SCPD) in the product portfolio management (PPM) context. The study contributes by clarifying the relationship between PMD/SCPD and PPM/SC 
processes including related PDM/PLM and ERP information systems. The most important scientific implication of this study is providing new understanding on the role of supply chain process related product data, the SCPD, in the context of MDM, PMD, and PPM. The findings are in line with (Cooper et al. 2001) in understanding that deficient information for PPM will result in a risk of serious negative consequences. The findings, however, provide new by taking another step towards the ability to report product level profitability in company product portfolios. Currently, the lack of fact-based and real-time PPM has led to situations where decisions are opinion-based, based on emotional criteria, and sometimes based on who shouts the loudest. The findings are in line with those studies that have understood that the necessary policies are missing from organisations (Haines 2008, Tolonen et al. 2014; Cooper et al. 2001). This study supports Silvola et al. (2011) in understanding that data, processes, and information systems are the main key elements in today's master data considerations. Support is provided for Silvola in highlighting the importance of defining master data in companies, while new contribution is created by attempting to convey the significance of SCPD for the PPM analysis. The findings contribute to the understanding that companies are not fully utilising the potential of PDM/PLM and ERP systems and indicate that disciplined definitions for PMD and SCPD are needed. This study is an initial endeavour to figure out the important connection between centralised MDM, PMD, and SCPD to support fact-based and real-time PPM in parallel with emotions and fluctuating opinions in decision-making.

\subsection{Managerial implications}

The managerial implications of this study include indicating the need to develop further fact-based PPM based on the PMD and SCPD meaning that companies must rethink their way of structuring and maintain the MDM concept. The SCPD and its connection to PMD 
need to be clearly defined to support fact-based PPM analysis and decision making. This study highlights how managers must understand PPM, PLM, PDM, and SC processes and related systems such as PDM/PLM and ERP, which are not fully utilised in companies, and that there are overlapping among data, processes, and systems, or potential lack of data contributing towards the current difficulty of taking PPM to a level of reporting product level profitability.

\subsection{Limitations and future studies.}

The limitations of this study involve the number of analysed companies. The scope of SCPD was also limited to product cost and sales price, although also other attributes such as production volume were recognised as factors for PPM through the entire product lifecycle. However, the product cost and sales price are the most crucial factors in PPM analysis and decision making. The study does not provide solution approaches for calculating product profitability or life-cycle costs, but focuses on the roles of data, processes, and information systems.

As future research, all PPM focus areas, strategic fit, value maximisation, and portfolio balance relating to all key business processes including sales, care and service processes would open a whole new contribution to further transfer from PLM to fact-based PPM on an enterprise ecosystem level. Moreover, since there is pretty much lack of research about the relationship between centralised MDM and business process related product data, future research is needed. 


\section{Conclusions}

This study focused on the role of product master data (PMD) and supply chain product data (SCPD) and their connection to more fact-based analysis and decision-making in product portfolio management (PPM). The study constitutes of analysing extant literature, the creation of construction for current state analysis and the analysis of relevant company practices and challenges.

This study indicates that the PMD and SCPD are not adequately defined, used and connected back to PPM analysis and decision-making in companies. The combinations of used information systems have typically evolved based on "fit-for-purpose" mentality instead of considering a wider perspective of master data management (MDM) and business processes. Fact based monitoring of product profitability should be possible by better utilisation of existing data and information systems by comparing the cost information and the sales price with the support of product structure. Also, the total lifecycle costs of products are not calculated regarding PPM. The data is in silos on information system level, and alternative tools such as Excel spreadsheets are used to narrow this gap. Thus, the entirety of the PMD and SCPD is fragmented into different information systems and additional applications. The findings indicate that the PLM concept is one of the key concepts in PPM.

\section{References}

Aiken, P., Billings, J., 2013. Monetizing data management. Unlocking the value in your organization's most important asset. Technics Publications, LLC U.S.A. 2013.

Ameri, F., Dutta, D., 2005. Product Lifecycle Management: Closing the Knowledge Loops. Computer-Aided Design \& Applications. Vol. 2, No 5, 577-590. 
Berriche, F. Z., Seddini, B., Kadima, H., Riviere, A., 2016. Closed-Loop Product Lifecycle Management Based on a Multi-agent System for Decision Making in Collaborative Design. Springer International Publishing AG 2016, F. Lehner and N. Fteimi (Eds.): KSEM 2016, LNAI 9983, pp. 540-551.

Borgia, O., Fanciullacci, N., Franchi, S., Tucci, M., 2015. The use of product information along its entire lifecycle: A practical framework for continuous development. Issue Industrial Systems Engineering. 2015, 177-182.

Cooper, R.G., Edgett, S.J., Kleinschmidt, E.J., 1999. New product Portfolio Management: Practises and Performance. Journal of Product Innovation Management 1999; 16(4): 333-351.

Cooper, R.G., Edgett, S.J., Kleinschmidt, E.J., 2001. Portfolio management for new product development: results of an industry practices study. $R \& D$ management 31(4): 361-380.

Daaboul, J., Le Duigou, J., Penciuc, D., Eynard, B. 2016. An integrated closed-loop product lifecycle management approach for reverse logistics design. Production Planning \& Control, 27:13, 10621077.

Doros, A., Dumitru, G. C., Irimescu, M. A., 2014. Product life cycle cost. Recent advances in mathematics, statistics and economics. Proceedings of the 2014 International Conference on Economics and Statistics (ES'14). 175-181.

Dunk, A. S., 2004. Product life cycle cost analysis: the impact of customer profiling, competitive advantage, and quality of IS information. Management Accounting Research 15 (2004) 401414.

Haapasalo, H., Ingalsuo, K., Lenkkeri, T., 2006. Linking strategy into operational management. A survey of BSC implementation in Finnish energy sector. Benchmarking: An International Journal. Vol. 13, Iss 6, 701-717.

Hadaya, P., Marchildon, P., 2012. Understanding product lifecycle management and supporting systems. Industrial Management \& Data Systems, Vol. 112, Iss 4, 559-583.

Haines, S, 2008. The Product Manager's Desk Reference. The United States of America: McGrawHill Osborne Media. 
Heller, J. E., Löwer, M., Feldhusen, J., 2014. Requirement based future Product Cost Estimation using Lifecycle Assessment Data. 21 $1^{\text {st }}$ CIRP Conference on Life Cycle Engineering. Procedia CIRP 15 (2014) 520-525.

Hulthén, H., Naslund, D., Norrman, A., 2016. Framework for measuring the performance of the sales and operations planning process. International Journal of Physical Distribution \& Logistics Management. Vol. 46, Iss 9, 809-835.

Jetson, J., Nelis, J., 2008. Business process management: practical guidelines to successful implementations. Amsterdam: Elsevier.

Jun, H.-B., Kiritsis, D., Xirouchakis, P., 2007. Research issues on closed-loop PLM. Computers in Industry. 58 (2007) 855-868.

Kiritsis, D., 2011. Closed-loop PLM for intelligent products in the era of the Internet of things. Computer-Aided Design. Vol. 43 (2011): 479-501.

Kotler, P., Armstrong, G., 2011. Principles of Marketing, 14 ${ }^{\text {th }}$ ed. Pearson Education Inc., New Jersey 07458 .

Kropsu-Vehkapera, H., Haapasalo, H., Harkonen, J., Silvola, R., 2009. Product data management practices in high-tech companies. Industrial Management \& Data Systems, Vol. 109, Iss 6, 758774.

Kropsu-Vehkapera, H., Haapasalo, H., Jaaskelainen, O., Phusavat, K., 2011. Product Configuration Management in ICT Companies: The Practitioners' Perspective. Technology and Investment, $2011,2,273-285$.

Kubler, S., Buda, A., Robert, J., Framling, K., Le Traon, Y. 2016. Building Lifecycle Management System for Enhanced Closed Loop Collaboration. 13th IFIP International Conference on Product Lifecycle Management (PLM16). Springer book Advanced ICT series.

Kumar Das, T., Mishra, M. R., 2011. A Study on Challenges and Opportunities in Master Data Management. International Journal of Database Management Systems. Vol. 3, No 2, 2011. 
Madenas, N., Tiwari, A., Turner, C.J., Woodward, J., 2014. Information flow in supply chain management: A review across the product lifecycle. CIRP Journal of Manufacturing Science and Technology 7, 335-346.

Marchetta, G., Mayer, F., Forradellas, R., 2011. A reference framework following a proactive approach for Product Lifecycle Management. Computers in Industry. 62, 672-683.

Merton, R., Fiske, M., Kendall, P., 1990. The Focused Interview: A Manual of Problems and Procedures. $2^{\text {nd }}$ ed. New York: The Free Press.

Porter, M.E, 1996. What is a strategy. Harward Business Review 74(6), 61-78.

Saaksvuori, A., Immonen, A., 2008. Product lifecycle management, $3^{\text {rd }}$ edition. Springer 2008.

Shin, J-H., Kiritsis, D., Xirouchakis, P., 2015. Design modification supporting method based on product usage data in closed-loop PLM. Internal Journal of Computer Integrated Manufacturing. Vol. 28, No 6, 551-568.

Silvola, R., Jaaskelainen, O., Kropsu-Vehkapera, H., Haapasalo, H., 2011. Managing one master data - challenges and preconditions. Industrial Management \& Data Systems, Vol. 111, Iss. 1, 146162.

Silvola, R., Tolonen, A., Harkonen, J., Haapasalo, H., 2018. Defining one product data for a product. International Journal of Business Information Systems. In press.

Silvola, R. 2018. One product data for integrated business processes. Doctoral thesis. Acta Universitatis Ouluensis. C686, Technica. University of Oulu. <Available Online> http://jultika.oulu.fi/files/isbn9789526221144.pdf

Srinivasan, S. R., Ramakrishnan, S., Grasman, S. E., 2005. Identifying the effects of cannibalization on the product portfolio. Marketing Intelligence \& Planning. Vol. 23, No 4, 359-371.

Sriti, M.F., Assouroko, I., Ducellier, G., Boutunaud, P. and Eynard, B. (2015). Ontology-based approach for product information exchange. International Journal of Product Lifecycle Management, Vol. 8, No. 1, pp.1-23. 
Stark, J. 2011. Product Lifecycle Management: 21st Century Paradigm for Product Realisation (2011) 2nd Edition. Springer-Verlag, London

Stark, R., Damerau, T., Hayka, H., Neumeyer, S., Woll, R. 2014. Intelligent information technologies to enable next generation PLM. In: Fukuda, S., Bernard, A., Gurumoorthy, B., Bouras, A. (eds.) PLM 2014. IAICT, vol. 442, pp. 485-495. Springer, Heidelberg.

Stark, J., 2016. Product Lifecycle Management. Vol. 2, The Devil is in the Details. Third Edition. Springer International Publishing Switzerland.

Tolonen, A, 2016. Product portfolio management over horizontal and vertical portfolios, 574. University of Oulu, Acta Universitatis Ouluensis C Technica.

Tolonen, A., Harkonen, J., Verkasalo, M., Haapasalo, H., 2015a. Product portfolio management process over horizontal and vertical portfolios. International Journal of Product Life Cycle Management 8(3): 189-215.

Tolonen, A., Kropsu-Vehkapera, H., Haapasalo, H., 2014. Product Portfolio Management - Current challenges and preconditions. International Journal of Performance Measurement, Vol. 4, No 2, 69-90.

Tolonen, A., Shahmarichatghieh, M., Harkonen, J., Haapasalo, H., 2015b Product Portfolio Management - Targets and key performance indicators for product portfolio renewal over the life cycle. International Journal of Production Economics, 170, 468-477.

Weber, C. and Werner, H. 2003. A different view on product data management/product life-cycle management and its future potentials. Journal of Engineering Design, 14(4), 447-464. 
Appendix A. Participants of the interviews in case companies

\begin{tabular}{|c|c|c|}
\hline $\begin{array}{c}\text { Case } \\
\text { company }\end{array}$ & The roles and the responsibilities of interviewees & \# of interviewee(s) \\
\hline $\mathbf{A}$ & $\begin{array}{l}\text { Program Manager (Product Engineering), Group } \\
\text { Controller, Technology Manager (Mechanics), IT } \\
\text { Architect, Electrical Design Engineer }\end{array}$ & 5 \\
\hline B & $\begin{array}{l}\text { Head of R\&D (HW), Product Data Manager, System } \\
\text { Manager (PDM/PLM), Mechanical Designer, } \\
\text { Electrical designer, Data Coordinator (ERP), Data } \\
\text { Coordinator (PDM), Product Manager }\end{array}$ & 8 \\
\hline $\mathbf{C}$ & $\begin{array}{l}\text { Manager of Business Solutions, Head of Business } \\
\text { Applications and Data Management, Manager } \\
\text { (Quality \& Process Development), Program } \\
\text { Manager, Mechanical Engineer, Electrical Engineer }\end{array}$ & 6 \\
\hline
\end{tabular}

Appendix B. Questionnaire for PDM/PLM IS landscape, MDM/PDM/PLM governance models, key processes, targets, and KPIs.

The case company privacy will be highly respected. All answers will be anonymised and handled with the high confidentiality.

1. Benchmark/interview session
a. Name(s) of interviewee(s)?
b. Role of interviewee(s)?
c. The relationship to the PDM/PLM?
d. Work experience?

2. The common company information

a. What is the headcount for the company? 
b. How many manufacturing sites and where located?

c. How many sales companies?

d. How many delivery centers?

3. Request to get a system map, including connections between tools and systems and their integrations, including at least CAD, PDM, PLM, ERP, PPM, CRM and other Sales tools, such as:

a. ECAD, MCAD, PDM, ERP, etc.

b. Sales tools, e.g., CRM

c. Product Portfolio Management tools

d. Other tools, e.g., MS Office or another corresponding.

e. What are tools used for PDM/PLM during the entire product lifecycle?

f. How is Product Master Data (PMD) classified and in which tool? Which are the original sources of PMD?

g. How the different tools are integrated, and which kind of data transferred between the systems?

4. PDM/PLM governance model and processes of the organisation

a. Who chairs the PDM/PLM organisation of the company?

b. Which kind of roles and responsibilities is in place in the organisation?

c. Which functions of the organisation are involved in PDM/PLM governance model? Is there any relevant function or team missing?

d. Who are the data owners through the entire product structure?

e. What are the main processes of the company related to PDM/PLM?

f. How is the item/product structure creation processes carried out within the entire PDM/PLM organisation? What are the main inputs of the processes? Who are the decision-makers in the processes? What is the outcome of the processes? 
g. What are the main targets and KPIs related to PDM/PLM?

5. Product cost calculation

a. In which system or tool, the products' own cost is calculated and maintained?

b. In which system or tool, the sales price of products is maintained?

c. Are the own cost and the sales price in the same system or tool? Moreover, in which system?

d. Is the product firmware cost included in the product own cost?

e. Is the service software cost included in the product own cost?

6. Master Data Management practices

a. How are the (Product) Material Master Data Management governance model, concept and/or practices maintained and documented?

i. In system level?

ii. In company level?

b. How are the Product Material Master attribute creation/maintenance roles and responsibilities organised?

7. Engineering Change Process
a. What are the roles and responsibilities in Engineering Change Process?
b. Who are the process customers?
c. What are the process targets and KPIs?
d. How is product data updated as a part of engineering change?

8. Other possible additional comments You think are relevant related to the questions above? 